\title{
NADA MEJOR QUE TENER UN BUEN DESIGUAL CERCA
}

\author{
Estanislao Antelo*
}

RESU M EN : Este ensayo pretende desplegar un esfuerzo por compartir el resultado provisional de un ejercicio de lectura sobre la obra de Jacques Rancière. En primer término, se analizan los problemas que la versión sobre las paradojas de la igualdad introducen en el pensamiento pedagógico igualitario. En segundo término se ofrece una interpretación de lo que un maestro ignorante emancipador puede hacer. Por último se intenta estimar la fuerza que puede proporcionarle a la pedagogía contemporánea la postulación de la igualdad de inteligencias, como nombres de la indocilidad y la libertad.

Palabras clave: Rancière. Pedagogía. I gualdad. M aestro. Libertad.

NOTHING IS BETTER THAN HAVING A GOOD UNEQUAL CLOSE

\begin{abstract}
ABST RACT : T his essay aims to develop an effort to share a provisional result of a reading of the work of Jacques $R$ ancière. First, some problems that his version of the paradoxes of equality introduce in egalitarian pedagogical thought are analyzed. Second, an interpretation of what an "ignorant teacher" can do is offered. Finally, the essay undertakes an estimation of the resources that the notion of the equality of intelligences - under the names of undocility and freedom - can offer contemporary pedagogy.
\end{abstract}

Key words: Rancière. Pedagogy. Equality. Teacher. Freedom.

Doctor en H umanidades y Artes, Universidad Nacional de Rosario (fLACSO), Argentina.

E-mail: anteloe@arnet.com.ar 
$\mathscr{P}$ articipar en un dossier sobre un libro cuyo autor afirma que los libros no precisan asistencia, ni servicios de nuestra lengua, es una tarea compleja. H asta se podría preguntar con Rancière, o decir lo que se piensa con sus palabras, con esas palabras de ese otro Rancière que se dirige a nosotros, lo siguiente: ¿Bastan las frases de Rancière para comprender las frases de Rancière y para decir qué es lo que de ellas se comprendió? ${ }^{1}$

Bastan.

Sin asistencia ni afán explicativo será entonces otro el atajo. Será, en todo caso, practicar aquello que gentilmente se nos ha cedido pero que por azar hemos atentamente conquistado: cierto uso inmediato de nuestra propia inteligencia, si es que al fin, alguna quiere haber. Llamemos con cautela a este ejercicio, ensayar, siempre que no perdamos de vista que quienes ensayan e interpretan son eso, intérpretes.

Cuenta Georges Steiner la ocasión en la que Schumann luego de interpretar una de sus obras difíciles, es consultado sobre el sentido de la misma. En el acto, el buen Schumann, vuelve a interpretar, a ejecutar la obra. Se sienta y la toca de nuevo (Steiner, 1991, p. 32).

Rancière toca un Joseph Jacotot y henos aquí sentados, reunidos para tocar el Jacotot de Rancière. Toquemos pues.

Q uien toma seriamente, quien consigue dejarse tomar seriamente por el conjunto de signos puestos a disposición por El maestro ignorante de Rancière no puede evitar someterse a esa conocida sensación de vísperas de desempleo. Se trata de la irrupción de un pensamiento sobre aquello que todavía no ha sido pensado en el terreno pedagógico. De ahí, su carácter interruptor. Como si efectivamente un grano de arena se hubiera introducido de golpe en el engranaje de la sabia pedagogía que pensamos y practicamos. Como si la vanidad del esfuerzo por comprender, a la que Rancière nos somete sin contemplación alguna, trajera sin miramientos la novedad: ya no más maestros progresistas explicadores se precisan. Ya no más pedagogos bienpensantes.

Un raro mutismo nos envuelve una vez que el convite no es lanzado. N uestra máquina de improvisar se detiene y cuesta hacer.

Si lo que cuesta todavía vale, voy a desplegar un esfuerzo austero por poner a disposición aquello que he podido y deseo verificar luego de semejante chirriar de la maquinaria pedagógica.

a - ¿D ietólogos de la igualdad?

Podríamos verificar la maniobra de Ranciére de la siguiente forma: nada mejor que tener un buen desigual cerca. Los administradores y 
perseguidores de la igualdad padecen una rara pasión primitiva: la desigualdad. De la misma manera que el pecado para el cura, el mundo material para el asceta 0 , el sedentario para el Personal Trainner, la desigualdad es el alimento de los igualitaristas, aquellos a los que Peter Sloterdijk por momentos ubica entre que practican un raro tipo de afecto, el afecto igualitario (Sloterdijk, 2002, p. 720).

M uchos de ellos son dietólogos en tanto su menester consiste en dosificar y reducir. Reducir la desigualdad. Los ingredientes para la dieta igualitaria están hechos de una conocida desmesura: el saber repartido, sazonado y explicado en tiempo y forma reduce distancias. Son dietólogos, en plural, porque son varios. H umanitarios, progresistas y conservadores. Lo mismo da.

Están aquellos otros que denuncian la vanidad de la dieta y apetecen explicar las reglas del saqueo, el reparto desigual y distintivo de ese lujo, lo simbólico. Son algo así como esclarecedores de conciencias pedagógicas, comprometidos sociopedólogos, cantores de educativas protestas:

vean ustedes, la escuela no es inocente. $\mathrm{N}$ o crean en la manganeta que promete igualdad en el reparto generoso de un fondo cultural común de conocimientos. Ese fondo es monetario, internacional, dominante. La escuela reproduce la cultura de sus amos y los deja afuera. La escuela reproduce la desigualdad y no puede hacer otra cosa. La escuela precisa de nosotros que, a no olvidarlo, no somos sus amos. La escuela precisa de nuestras explicaciones esclarecidas. Sólo nuestra clara explicación de ese saqueo podrá liberarlos de ese yugo. No crean en los intentos por repartir la torta cultural de manera más democrática. La escuela, al fin, vive de esa desigual dad que nosotros nombramos o, lo que es la misma cosa, sin esa escuela cretina reproductora, nosotros no existimos.

Son los que gustan de explicar a las gentes pobres que no saben lo que hacen.

En mi país, por ejemplo, abundan los que frente al estremecimiento sincero que la proliferación del embrutecimiento les provoca, deciden "trabajar con lo que haiga". Se lanzan a la ingrata y minúscula tarea de educar con el contexto, con lo que el niño trae, con lo cercano, con aquello que pueda ser acceible a los de abajo, los inferiores, los que no saben. Son los que saben qué es lo necesariamente accesible para los que no tiene acceso. Gustan de usar repetidas veces la palabra dignidad. Arman talleres, torneos y posgrados en dignidad. Son gente de Bien y saben siempre lo que los otros, pobres, necesitan y proceden a cocinar sus dietéticos, compasivos y siempre vernáculos manjares igualitarios. Como señala Abraham aman la democracia que siempre pretende nivelar, 
igualar y equiparar, con una culposa visión de la Justicia que no entiende que la dignidad de las personas consiste en superar su estado y no en que vengan los compasivos a igualárselo (Abraham, 2002, p. 61).

También compiten por el trofeo de la igualdad aquellos sociopedólogos que advierten que el darle "todo a todos" puede terminar por dejar a la corporación sin empleo y rectifican su dieta proponiendo lo que llaman con evidente mal gusto, discriminación positiva, esto es, "darle más al que menos tiene". La contabilidad que practican se basa en la creencia en que la inteligencia es una alacena diferenciada en la cual, a más acumulación, más igualdad. G ustan de usar las palabras compensar, atenuar, retardo, competencias, deficiencias y atraso.

Pero también están los nostálgicos del canon. Acusan a los progresistas del colapso de la escuela y repiten en todas las lenguas un verbo: volver. Back to basics. Estos, más inocentes, ya no asustan a nadie, tan sólo odian la igualdad y proporcionan temas para los papers de los pedagogos críticos.

Lo que Rancière no cesa de repetir es lo siguiente: para acá o para allá, la igualdad sigue siendo para ustedes, un objetivo a alcanzar o del cual sospechar. Y la igualdad jamás viene después. La igualdad no precisa dietólogos. H ay más: el deporte de la pedagogía dietética no hace más que confirmar una incapacidad en el mismo acto que intenta reducirla. Este acto tiene un nombre: embrutecer. Esto es lo que aconteció unos años atrás cuando, en ocasión de ser invitado a hablar sobre las dificultades de los aprendizajes escolares, fui presentado como un especialista en "fracaso escolar". Un "experto" en fracaso escolar. Luego, habrá de haber un congreso en Fracaso Escolar. Luego un doctorado en Fracaso Escolar. Luego un foro mundial de fracasados escolares en el que los expertos explicaremos. Así se procede.

Pero para el traductor de Jacotot, la igualdad - que es siempre la de al menos dos seres parlantes - no se persigue, no se reivindica, no se provee ni se concede. Se practica y se anuncia. Se trata de una suposición a ser mantenida en cualquier circunstancia, contra toda prueba empírica en su contra.

\section{b - ¿M aestros ignorantes?}

¿Se puede aprender sólo? Se puede. Pero no es aquí ninguna nodirectividad la que avanza. No es aquí ningún método el que pide su lugar. $\mathrm{N}$ i siquiera es ninguna de las viejas eternas nuevas pedagogías. 
Usted puede si quiere. Sí, pero no estamos frente a un nuevo anuncio publicitario. No es, por cierto, el simpático, atlético y prometeico Just do it. No estamos frente a la promesa de los educadores emprendedores, recursos humanos tomadores de riesgos, custodios de esa nueva sociedad del conocimiento.

$\mathrm{N}$ o se aprende sin maestros. Pero tampoco se aprende con maestros comunicadores, proveedores de lo que a los otros les falta. Tampoco el maestro es un guía, un acompañante, un facilitador o esos desatinos. En todo caso es el propio maestro el que puede ser aprendido: observarlo, imitarlo, disecarlo, recomponerlo y luego, quizás, quitárselo de encima. Al fin, un maestro no es más que un invento del discípulo. Al fin y al cabo, como la patria, que es un efecto del exilio (Braunstein, 1995, p. 33) y, a contrapelo de toda didáctica, la enseñanza no es sino un efecto del aprendizaje pero nunca al revés.

Un maestro ignorante habla para hacer hablar. Dice por ejemplo: es preciso aprender. Pero aprender es un acto, como decía, que funda la enseñanza que lo causa. El imperativo no es entonces instruir. Tal vez atestiguar, testimoniar. Cierto que un maestro bien puede ser intratable. Pero puede poner a disposición, libros, variedad de signos y constatar un movimiento, una atención: hay aquí una inteligencia en movimiento. $\mathrm{N}$ o constata si alguien aprendió sino si buscó. $\mathrm{N}$ o sigue un procedimiento sino una señal de confianza. No procede por etapas ni ambiciona adecuar. Señala y recuerda, a cada paso, la cómoda posición de quién renuncia a lo que puede, aquel que triunfa, de algún modo, al fracasar.

M ás aún, ninguna piedad con las víctimas y los falsos modestos. Con los yo no puedo. N inguna negociación para los que suscriben el veredicto de su propia exclusión y practican el desprecio de sí mismos. Ninguna contemplación con los que ignoran deliberadamente, abdicadores, gozosos temerosos. La ignorancia nunca es inocente.

$H$ ay, puede haber en esa relación entre maestro y aprendiz, yugo. $\mathrm{H}$ ay, puede haber sujeción. $\mathrm{H}$ ay, puede haber férula. $\mathrm{H}$ ay, puede haber el viejo, arbitrario y autoritario porque te lo digo yo. Ahí tienes Fénelon. Porque te lo digo yo. Sujeción y subordinación. Sin embargo, no es necesariamente ahí donde lo bruto toma lugar.

Los problemas comienzan cuando una voluntad pretende sujetar una inteligencia. Los problemas comienzan cuando es la inteligencia de otro parlante (el desigual en tanto mudo ignorante) la que, en nombre de su ignorancia y por el bien de su ignorancia, se sujeta. Pero no se va muy lejos por este camino. La inteligencia es para Rancière uno de los 
nombres de la libertad. Y la libertad se toma, ella se conquista y se pierde solamente por el efuerzo de cada uno. La voluntad no puede con el carácter indómito, indócil de un no-bruto, un emancipado, aquel que persiste en el uso de su fuerza intelectual. La inteligencia sólo obedece su propio curso. De ahí que aquel que, sin saber, terminaría por fundar las coordenadas básicas de nuestra pedagogía progresista republicana, localizara la tarea educativa en la domesticación de esa indocilidad radical. Como señala Slavoj Žžek,

en la Pedagogía de Kant, se encuentra todo: desde el tema foucaultiano de la micropolítica disciplinaria anterior a cualquier instrucción positiva, hasta la equiparación althusseriana del sujeto libre con el sujeto sometido a la ley. Pero su ambigüedad fundamental no es menos discernible; por una parte, Kant parece concebir la disciplina como el procedimiento que libera al animal humano, sustrayéndolo a los instintos naturales; por otro lado, está claro que el objetivo de la disciplina no es directamente la naturaleza animal del hombre, sino su excesivo amor a la libertad, su natural indocilidad, que va mucho más allá que los instintos de obediencia del animal. (Žžek, 2001, p. 48)

En esto, en la domesticación de esta indocilidad radical, consiste la meta fundamental dela educación. (Žžek, 1998, p. 69)

¿Se puede instruir siendo ignorante? Se puede a condición de localizar qué es lo que el que no sabe, sabe. El maestro, testarudo que deambula por el país de los signos, busca compañeros de viaje y parte de trazar el inventario de esa ignorancia supuesta. El maestro ignorante más que saber que no sabe, sabe también que el otro puede saber. Y entonces, se dirige a él, lo interroga, le habla, lo provoca. Educar es tener con quien hablar.

Pero el que quiere hablar no es Sócrates, la sabia partera. Sócrates la partera nos conduce al saber que habita en cada cual. Pero el trayecto que el intermediario Sócrates propone tiene un fin sabido con anticipación. El Socratismo es una forma perfeccionada de embrutecimiento. Como todo maestro sabio, Sócrates interroga para instruir. En todo embrutecedor habita una partera. Aquellos cerrajeros que disponen del acceso al saber, de esa llave, practicarán el arte de la postergación infinita.

¿Y qué sabe el no-partero maestro ignorante? Sabe, como D eleuze traduce en su $\mathrm{N}$ ietzsche, que el débil o el esclavo no es el que tiene menos fuerza sino aquel que teniendo la fuerza que tenga, está lejos de lo que puede. Aquel distraído, apartado de lo que puede. Si se puede aprender es en tanto el maestro verifica que el otro es un indócil. Y, lo indócil, es el nombre de lo que nos empuja a no separarnos de lo que 
podemos. La indocilidad, que acá llamamos libertad, no resiste jerarquías, no se puede ceder en tanto es el nombre de lo que no cede. Constatar esta perogrullada es lo que Rancière llama emancipar. Embrutecer no es más que predisponerse a sustraer en el otro el uso de su propia indocilidad. Acallarlo. D etenerlo. Por el contrario, un maestro emancipador está ahí para decir siga, no se detenga, no se aparte, persevere, continúe. N o se distraiga, esté atento que hay signos por venir y cosas por inventar. No se es humano suspendido y a la espera. No cese. Q ue nadie moleste al niño mientras su inteligencia trabaja. La apropiación del mundo de los signos exige constancia y fidelidad a lo que se es capaz.

0 , como diría Alain Badiou, se trata de llevar hasta el fin la posibilidad de que al otro algo, por más ínfimo que sea, le pueda suceder. Porque un otro es siempre alguien que es otra cosa que un animal, otra cosa que una víctima: bestia resistente diferente de los caballos, no por su cuerpo frágil, sino por su obstinación en persistir en lo que es, es decir, precisamente, otra cosa que un animal (Badiou, 1995, p. 104). Y una otra cosa que un animal es aquel que al serle dirigida una palabra, quiere algo decir y quiere algo escuchar. $\mathrm{H}$ asta nuevo aviso, los animales no parlotean. Sólo responden a las señales y estímulos dosificados que habitan los diccionarios últimos de los pedagogos.

Recebido e aprovado em fevereiro de 2003.

\section{N ota}

1. Todas las cursivas que no se acompañan de referencia bibliográfica pertencen al libro de Rancière.

Referencias bibliográficas

ABRAH AM , T. Pensamiento rápido. Buenos Aires: Sudamericana, 2002.

BADIOU , A. La etica: ensayo sobre la conciencia del mal. In: Aвrah am, T. Batallas eticas. Buenos Aires: N ueva visión, 1995.

BRAU N STEIN, N. El goce. 2. ed. M éxico: Siglo XXI, 1995.

DELEUZE, G. N ietzsche y la filosofía. Barcelona: Anagrama, 1993.

RAN CIĖRE, J. El desacuerdo: política y filosofía. Buenos Aires: N ueva visión, 1996. 
RAN CIĖRE, J. 0 mestre ignorante: cinco lições sobre a emancipação intelectual. Belo H orizonte: Autêntica, 2002.

SLOTERDIJK, P . Extrañamiento del mundo. Valencia: Pretextos, 1998.

SLOTERDIJK, P. El desprecio de las masas. Valencia: Pretextos, 2002.

乙̌ŽK, S. Goza tu śntoma! Buenos Aires: N ueva Visión, 1994.

$\check{Z} \check{\mathbb{Z} K K}$, S. Porque no saben lo que hacen: el goce como factor político. Buenos Aires: Paidós, 1998.

乙̌泟K, S. El espinoso sujeto: el centro ausente de la ontología política. Buenos Aires: Paidós, 2001. 